\title{
Evaluation on the Strength Recovery Rate of Concrete Using Surface Coating Agent
}

\author{
Hyeok Jung Kim ${ }^{1}$, Nam Wook Kim ${ }^{2, ~ * ~}$ \\ ${ }^{1}$ Industry-Academic Cooperation Foundation Center, Hankyong National University, Anseong, Republic of Korea \\ ${ }^{2}$ Department of Civil and Environmental Engineering, Jeonnam State University, Damyang, Republic of Korea
}

\author{
Email address: \\ nwkim@dorip.ac.kr (N. W. Kim) \\ *Corresponding author
}

\section{To cite this article:}

Hyeok Jung Kim, Nam Wook Kim. Evaluation on the Strength Recovery Rate of Concrete Using Surface Coating Agent. American Journal of Civil Engineering. Vol. 9, No. 1, 2021, pp. 18-24. doi: 10.11648/j.ajce.20210901.13

Received: January 13, 2021; Accepted: January 20, 2021; Published: March 26, 2021

\begin{abstract}
Cracks and voids of concrete cause the loss of durability. When the cracks reach to the surface of reinforced concrete structures, they can repair by various methods, but there are no effective repairing methods for latent faults or microcracks caused by load repetition because they cannot detect by surface state. In this study, we examined the presence or absence of self-repair performance of concrete mixed with the admixture using the coating material for repair, which has been used for a long time. Thus, the basic characteristics of concrete mixed with admixture were identified and self-repair performance was confirmed through experiments. As a result of considering the recovery of the strength of damaged concrete, concrete mixed with a surface coating agent showed a greater recovery effect than concrete mixed with non-mixed concrete. This effect is greater with the age of the damaged material. This shows that even if the repair coating material is mixed as an admixture, the crystal proliferation effect is maintained, and it is confirmed that the concrete mixed with the admixture has self-repairing performance.
\end{abstract}

Keywords: Strength Recovery Rate, Surface Coating Agent, Self-repairing, Maintenance, Durability

\section{Introduction}

Cracks and voids in concrete cause the durability of concrete structures to deteriorate. Cured concrete has gaps due to entrap air mixed in when kneading, waterways produced in the process of bleeding, gaps due to loss of moisture in fresh concrete, and potential defects such as plastic contraction and subsidence cracks. [1-3]

Furthermore, microcracks are formed inside hardened concrete in accordance with repeated loads during use. Water and carbon dioxide enter these cracks and voids, causing the loss of durability such as neutralization of concrete, salt damage, freezing damage, acceleration of alkali aggregate reaction, and lack of watertightness. [4-6]

Among these defects, plastic contraction cracks and subsidence cracks are repaired with mortar or epoxy resin. In addition, epoxy resin is applied to the surface or pressed into the cracked parts even if they cause concern about durability. These repairs are recognized for cracks on the surface of structures and parts.

It is done at the stage of peeling, and there is no effective way to deal with the occurrence of internal microcracks caused by latent defects or repeated stress inside concrete that cannot be seen from the surface. In addition, surface application and press fitting at the cracked part need to be dealt with again when new cracks occur, imitating an increase in maintenance costs. [7, 8]

Accordingly, if concrete is developed that can repair cracks and voids themselves, maintenance costs can be reduced.

Regarding the development of self-repair concrete, a method is under consideration to confine the repair agent in a capsule and include it in the concrete without reaction. However, this method does not work unless the capsules contained are torn by cracks.

In recent years, calcium hydroxide and unhydrated cement, 
which exist in concrete, have been used to develop repair materials capable of repairing voids and cracks. This repair material is applied to the surface of the cracked concrete member, but it is not used to fill the surface with cracks, it is repaired by proliferating new crystals in the concrete.

This research aims to develop concrete with self-repair performance against cracks by mixing this repair material into fresh concrete in advance as admixture (hereinafter referred to as surface coating agent). [9-12]

For this reason, the following two items were examined through experiments, that is confirmation of basic characteristics of concrete using coating repair material as admixture and confirmation of self-repair performance.

\section{Surface Coating Agent}

The material used in this study as a special admixture was developed as a coating repair material and is an inorganic powder. Its chemical composition is like portland cement as shown in Table 1 and Figure 1, but it contains less $\mathrm{CaO}$ and more $\mathrm{SiO}_{2}$ than portland cement. [13-14]

The raw materials are portland cement silica sand and contain catalysts that promote crystal proliferation in concrete. Cement produces cement hydrate such as ettringite, calcium hydroxide, and C-S-H crystals because of hydration reaction. Among these hydrates, C-S-H crystals are highly related to concrete strength, while calcium hydroxide crystals fill voids but do not contribute much to strength. As shown in Figure 1, catalysts contained in special admixture use unhydrated cement remaining in hardened concrete to produce C-S-H crystals. The process is outlined as follows.

Firstly, the catalyst reacts with calcium ions in concrete to form a calcium complex which is easy to diffuse in concrete. Secondly, the complex diffuses into micro cracked surfaces, releases calcium ions when unhydrated cement is present, and returns to the catalyst.

Thirdly, the released calcium ions react with water and unhydrated cement to form a C-S-H crystal.

Fourth, the catalyst releasing calcium ions reacts with the calcium ions in the concrete again to form a calcium complex.

This reaction process occurs repeatedly if water and undiluted cement exist. When used as a coating material for repair, mix it with water and apply it to the cracked concrete surface. The applied repair material penetrates the crack and causes the above reaction on the crack surface to repair the crack. The coating material for repair has already been used for actual repair work. [15-16]
Table 1. Chemical compositions used SCA and portland cement (\%).

\begin{tabular}{lll}
\hline Items & Surface coating agent (SCA) & Portland cement \\
\hline $\mathrm{CaO}$ & 35.0 & 65.0 \\
$\mathrm{SiO}_{2}$ & 37.5 & 2.5 \\
$\mathrm{Al}_{2} \mathrm{O}_{3}$ & 4.0 & 5.5 \\
$\mathrm{Fe}_{2} \mathrm{O}_{3}$ & 2.5 & 3.5 \\
$\mathrm{MgO}$ & 4.5 & 1.3 \\
$\mathrm{~K}_{2} \mathrm{O}$ & 5.5 & 0.5 \\
Catalyst & 1.8 & 0 \\
\hline
\end{tabular}

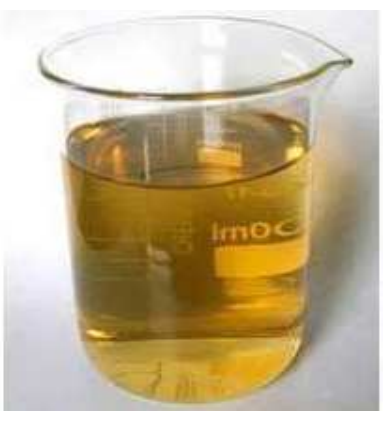

Figure 1. Surface coating agent.

\section{Mechanical Properties of Concrete Mixed with Surface Coating Agent}

The surface coating agent was developed as a coating material for repair, and there has never been a case in which it was mixed into concrete. Therefore, in this study, we examined the effects of special admixture on the slump of fresh concrete, the amount of air and the compressive strength of hardened concrete, the modulus of elasticity, and water permeability through experiments.

\subsection{Used Materials and Mix Proportion}

The cement used in the experiment was usually Portland cement, with mountain sand as a fine aggregate using AE water reducing agent as an admixture and crushed stone as a coarse aggregate.

The maximum coarse aggregate dimensions are $25 \mathrm{~mm}$, and it is decided the mix proportion for the target slump is $100 \pm 10 \mathrm{~mm}$ and air volume is $5 \pm 0.5 \%$.

For concrete (SCA-Con) using surface coating agent, the amount of surface coating agent mixed was set at $3 \%$ of the cement amount. For comparison purposes, concrete (NA-Con) without surface coating agent was also made. Each mix proportion is shown in Table 2.

Table 2. Mixing design of specimen.

\begin{tabular}{llllllll}
\hline \multirow{2}{*}{ Kinds } & \multirow{2}{*}{ W/C $(\%)$} & \multicolumn{2}{l}{ Unit weight $\left(\mathbf{k g} / \mathbf{m}^{\mathbf{3}}\right)$} & & \\
\cline { 3 - 8 } & & Water & Cement & Fine aggregate & Coarse aggregate & Normal Admixture & Surface coating agent \\
\hline NA-Con & 50 & 170 & 340 & 730 & 1035 & 1.7 & 1.7 \\
SCA-Con & 50 & 170 & 340 & 730 & 1035 & 11.9 \\
\hline
\end{tabular}

\subsection{Properties of Fresh Concrete}

To examine the effects of surface coating agent on consistency of fresh concrete, slump and air volume tests were conducted. Both tests were usually conducted on six batches of NA-Con and SCA-Con. The test results are shown in Table 3. According to the results of the slump test, the 
average slump value of SAC-Con. in all batches increased by about $30 \mathrm{~mm}$. On the other hand, in terms of air volume, concrete has decreased in all batches.

Thus, the consistency tends to decrease in SCA-Con. This is thought to be because the special admixture is spherical particles, and the effect of the ball bearing improves the fluidity. Accordingly, the unit water volume can be further reduced by mixing a surface coating agent.

In general, the difference of $1 \mathrm{~cm}$ in slump value corresponds to the difference of $1.2 \%$ in unit water amount, so according to the results of this experiment, the same slump value can be obtained even if the unit water amount of $3.6 \%$ is reduced. The unit water reduction effect of a normal water reducing agent is $4-8 \%$, and it is possible that the surface coating agent has the same water reduction effect as this.

If the unit cement quantity is equal, the reduction in the unit water quantity will reduce the $\mathrm{W} / \mathrm{C}$, which will increase the strength of concrete. Accordingly, high strength concrete can be obtained by using a surface coating agent. Furthermore, a reduction in the unit water volume reduces the amount of bleeding water, reduces potential defects such as water channels, and is effective in reducing dry shrinkage.

On the other hand, the amount of air is reduced due to the inclusion of surface coating agent, so if special consideration is required for the freezing and thawing action, we must be careful about its use.

Table 3. Test results of fresh concrete.

\begin{tabular}{lllll}
\hline \multirow{2}{*}{ Specimen } & \multicolumn{2}{l}{ Slump $(\mathbf{m m})$} & Air $(\%)$ \\
\cline { 2 - 5 } & NA-Con & SCA-Con & NA-Con & SCA-Con \\
\hline Test-1 & 105 & 120 & 5.1 & 4.5 \\
Test-1 & 100 & 122 & 5.2 & 4.4 \\
Test-1 & 110 & 115 & 4.9 & 4.6 \\
Test-1 & 107 & 121 & 5.0 & 4.3 \\
Test-1 & 109 & 118 & 4.8 & 4.4 \\
Test-1 & 106 & 119 & 5.1 & 4.6 \\
Test-1 & 111 & 121 & 4.9 & 4.3 \\
Test-1 & 110 & 117 & 5.0 & 4.5 \\
Test-1 & 98 & 120 & 5.1 & 4.6 \\
Test-1 & 103 & 116 & 5.2 & 4.4 \\
Average & 106 & 119 & 5.03 & 4.46 \\
\hline
\end{tabular}

\subsection{Properties of Hardened Concrete}

(1) Compressive strength

The compressive strength test is based on a standard $\Phi 100^{\times} 200 \mathrm{~mm}$ cylinder specimen. The test specimen was demolded within one day of placing and cured underwater at a water temperature of $20^{\circ} \mathrm{C}$ until the test.

The test material age was 7, 14, 28, 91 days, 6 months and 1 year and the test results were shown in Figure 2.

As the result of figure, the strength of SCA-con using surface coating agent is about $10 \%$ higher than that of NACon using normal admixture.

(2) Elastic modulus

Strain measurement was performed at the same age as the compressive strength test to determine elastic modulus. The number of tests was five for each material age.

To attach strain gauges to strain measurement, the specimen was taken out of the curing water tank two days before the test and air-dried until the test date. Figure 3 shows the change in elastic modulus with each material age.

As for the elastic modulus, SCA-Con has increased by about 1.5 2.5 GPa in each material age compared to NA-Con using normal admixture.

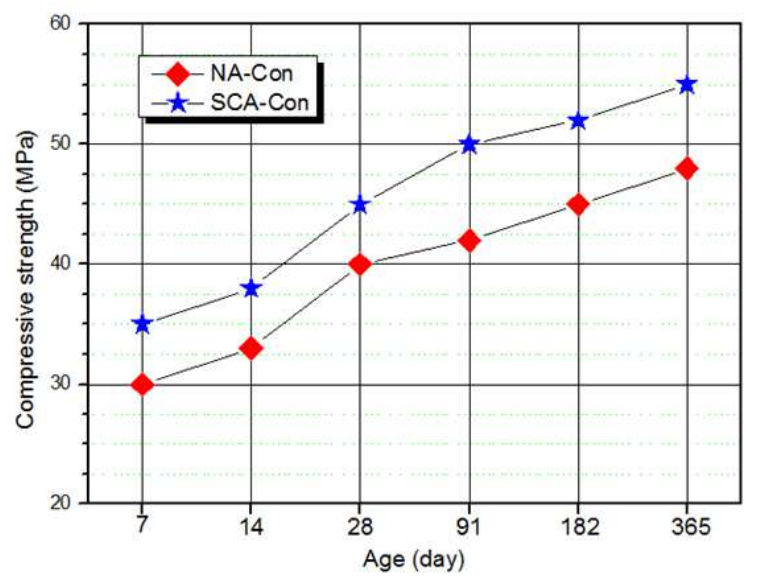

Figure 2. Result of compressive strength.

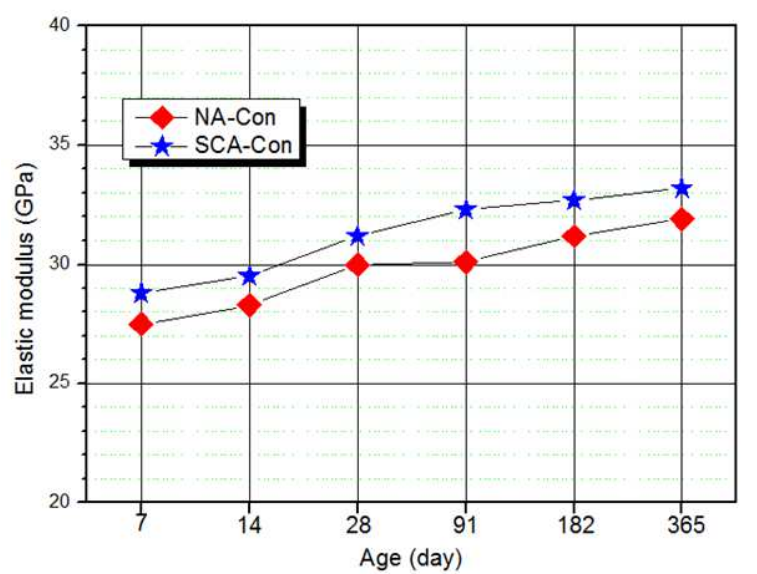

Figure 3. Result of elastic modulus.

(3) Coefficient of permeability

Watertightness of concrete is an important performance for dams and water structures. Furthermore, even in other structures, the penetration of water promotes deterioration of concrete, which is closely related to durability.

Therefore, in this study, we measured the permeability coefficient and examined the watertightness of SCA-Con and NA-Con.

In this study, the water permeability coefficient was measured by the output method. The test specimen used for the test is a hollow cylindrical test specimen with a height direction of $15 \mathrm{~cm}$ in diameter, $30 \mathrm{~cm}$ in height, and $2 \mathrm{~cm}$ in diameter in the center. Figure 4 shows the permeability test.

In the output method, the upper and lower surfaces of this specimen are watertight and water-permeable by applying 3.5 $\mathrm{MPa}$ of water pressure from the side. Water permeated through concrete is discharged out of the hollow part of the center. The coefficient of permeability is calculated by the 
following equation. [17]

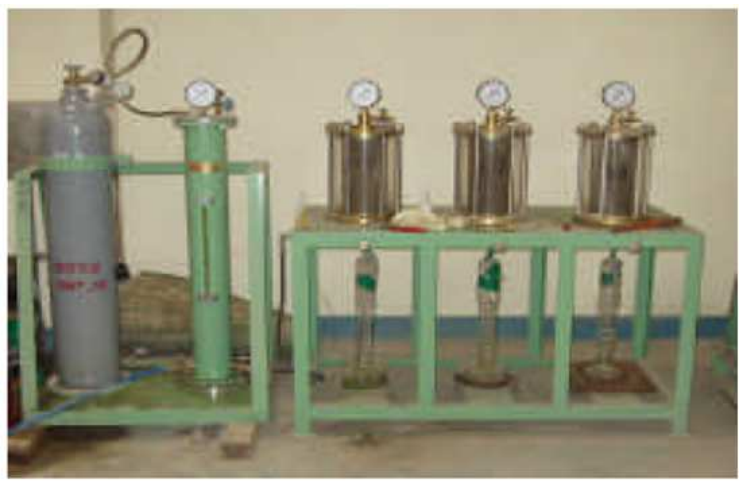

Figure 4. A view of permeability test.

$$
k=\frac{L}{A} \times \frac{Q}{\Delta h}
$$

Here, $k$ : Coefficient of permeability $(\mathrm{m} / \mathrm{s}), L$ : Specimen thickness $(\mathrm{m}), A$ : Specimen area $\left(\mathrm{m}^{2}\right), Q$ : Volume of water flowing in at unit time $\left(\mathrm{m}^{3} / \mathrm{s}\right), \Delta h$ : Difference in pressure head $(\mathrm{m})$

In this experiment, concrete with $\mathrm{W} / \mathrm{C}=70 \%$ was used, because $\mathrm{W} / \mathrm{C}=50 \%$ was not sufficient and the permeability coefficient could not be determined. The water permeability coefficient obtained because of measurement is, NA-Con is $4.5 \times 10^{-8} \mathrm{~cm} / \mathrm{s}$ and SCA-Con is $7.6 \times 10^{-9} \mathrm{~cm} / \mathrm{s}$, so the permeability coefficient of SCA-Con is about $16.9 \%$ that of NA-Con.

\section{(d) Discussions}

Based on the above test results on hardened concrete, we can see that the strength, elastic modulus, and watertightness of SAC-Con exceed NA-Con and that performance of concrete is improved by mixing surface coating agent.

In particular, the results of experiments on watertightness suggest that SAC-Con has fewer internal voids and is densified than NA-Con. This can be seen from the results of the elastic modulus test.

This is thought to be since crystal proliferation has progressed more than NA-Con due to the action of the surface coating agent, and that the internal fine voids have been filled. Furthermore, it is thought that the higher compression strength obtained by SAC-Con proves that the $\mathrm{C}-\mathrm{S}-\mathrm{H}$ crystal is proliferating because of this crystal proliferation.

On the other hand, the amount of fresh concrete air has decreased due to the inclusion of a surface coating agent. Since the amount of air affects the durability of concrete, this must be considered separately.

From the experiments on the basic characteristics of concrete described above, it was found that the performance of both fresh and hardened concrete was improved by mixing a repair coating material.

\section{Properties of Self-repair}

As mentioned above, this material is applied to the surface crack of concrete to restore concrete by accelerating crystalline growth on the surface. This study aims to examine whether the effect of promoting crystal proliferation is maintained even if it is mixed into concrete in advance as an admixture. The study was conducted using the recovery rate of compressive strength.

\subsection{Testing Method}

To confirm the self-repair effect of the special admixture, we conducted an experiment to check the change in compressive strength by compressing and recompressing the specimen once subjected to compressive stress after curing for a certain period. Here, based on the strength obtained by the initial compression, the strength recovery rate for recompression was defined as follows.

$$
R_{S}=\frac{R-\operatorname{Comp}}{I . S}
$$

Here, $R_{S}$ : Recovery rate of strength(\%), R-Comp: Recompressive strength (MPa) I.S: Initial compressive strength $(\mathrm{MPa})$

The test specimen was demolded one day after placing and cured in water. The test material age for initial compression, and re-compression was set to 10 types shown in Table 4.

For each pattern, 3 specimens of SAC-Con and NA-Con were made. The combination used is shown in Table 2. Loading was carried out until the maximum stress was generated in the specimen, whether initial compression, or recompression. However, in both loading tests, loading was stopped before the final destruction. However, some of the tests clearly resulted in the final destruction, so we excluded such specimens from the analysis of the test results.

Table 4. Specimen types of compressive strength recovery rate test.

\begin{tabular}{llll}
\hline \multirow{2}{*}{ Type } & Age(day) & & \\
\cline { 2 - 4 } & $\mathbf{1}^{\text {st }}$-compression & $\mathbf{2}^{\text {nd }}$-compression & $\mathbf{3}^{\text {rd }}$-compression \\
\hline F14-T14-1 & 14 & 0 & 0 \\
F14-T28-2 & 14 & 14 & 0 \\
F14-T42-3 & 14 & 14 & 14 \\
F14-T42-2 & 14 & 28 & 0 \\
F14-T70-3 & 14 & 28 & 28 \\
F28-T28-1 & 28 & 0 & 0 \\
F28-T42-2 & 28 & 14 & 0 \\
F28-T56-3 & 28 & 14 & 14 \\
F28-T56-2 & 28 & 28 & 0 \\
F28-T84-3 & 28 & 28 & 28 \\
\hline
\end{tabular}

\subsection{Test Results}

Table 5 shows the results of the initial compressive strength, re-compressive strength and the strength recovery rate of the specimen, which was initially compressed at the age of 14 days. Table 6 shows the results of initial compression at the age of 28 days.

The original strength increases between the 14th and 28th days of material age shown in Figure 2 was $33.3 \%$ for NACon and $28.6 \%$ for SAC-Con. As a result of 14 days of water curing, the strength of both increased by about $30 \%$. 
Table 5. Results of compressive strength and recovery rate at 14 days of initial age.

\begin{tabular}{lllll}
\hline \multirow{2}{*}{ Type } & \multicolumn{2}{l}{ Compressive strength (MPa) } & \multicolumn{2}{l}{ Recovery rate (\%) } \\
\cline { 2 - 5 } & NA-Con & SSA-Con & Na-Con & SSA-Con \\
\hline F14-T14-1 & 30 & 35 & 100 & 100 \\
F14-T28-2 & 28.5 & 36.9 & 95 & 105.4 \\
F14-T42-3 & 27.3 & 36.5 & 91 & 104.3 \\
F14-T28-2 & 33.1 & 40.5 & 110.3 & 115.7 \\
F14-T70-3 & 29.2 & 40.3 & 97.3 & 115.1 \\
\hline
\end{tabular}

Table 6. Results of compressive strength and recovery rate at 28 days of initial age.

\begin{tabular}{lllll}
\hline \multirow{2}{*}{ Type } & \multicolumn{2}{l}{ Compressive strength (MPa) } & \multicolumn{2}{l}{ Recovery rate (\%) } \\
\cline { 2 - 5 } & NA-Con & SSA-Con & Na-Con & SSA-Con \\
\hline F28-T28-1 & 40 & 45 & 100 & 100 \\
F28-T42-2 & 42.3 & 45.9 & 105.8 & 102 \\
F28-T56-3 & 38.2 & 44.5 & 95.5 & 98.9 \\
F28-T56-2 & 42.8 & 47.5 & 107 & 105.6 \\
F28-T84-3 & 39.5 & 48.6 & 98.8 & 108 \\
\hline
\end{tabular}

\subsection{Strength Recovery Rate}

Figure 5 and Figure 6 show the change in strength recovery rate when the initial compression material age is 14 days and when the initial compression material age is 28 days. In the case of the initial compression material age of 14 days, the recovery rate of SAC-Con exceeded that of NA-Con under all the test conditions.

Even in the case of the initial compression material age of 28 days, the recovery rate of SAC-Con exceeded that of NA-Con except when recompression was performed 14 days later. Furthermore, the difference in recovery rates between ordinary concrete and SAC-Con can be seen more significantly in the case of recompression than in the case of recompression.

In NA-Con, the strength is restored by curing after recompression, but the strength is no longer restored by recompression. On the other hand, the strength of SAC-Con has been restored even in re-compression.

Even in the specimen of F28-T56-3, which showed little strength recovery, the reduction in strength in re-compression was small, and the strength was almost equal to that in initial compression.

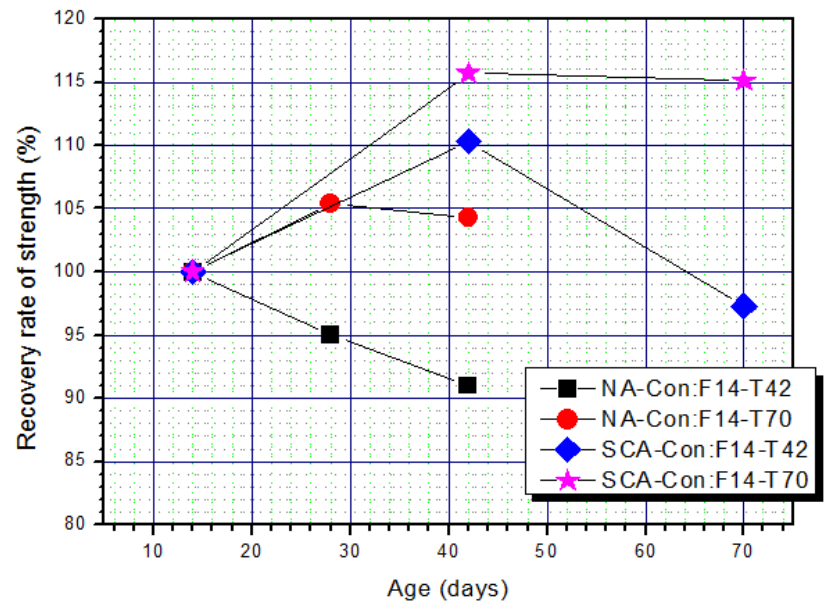

Figure 5. Recovery rate of strength at 14 days of initial age.

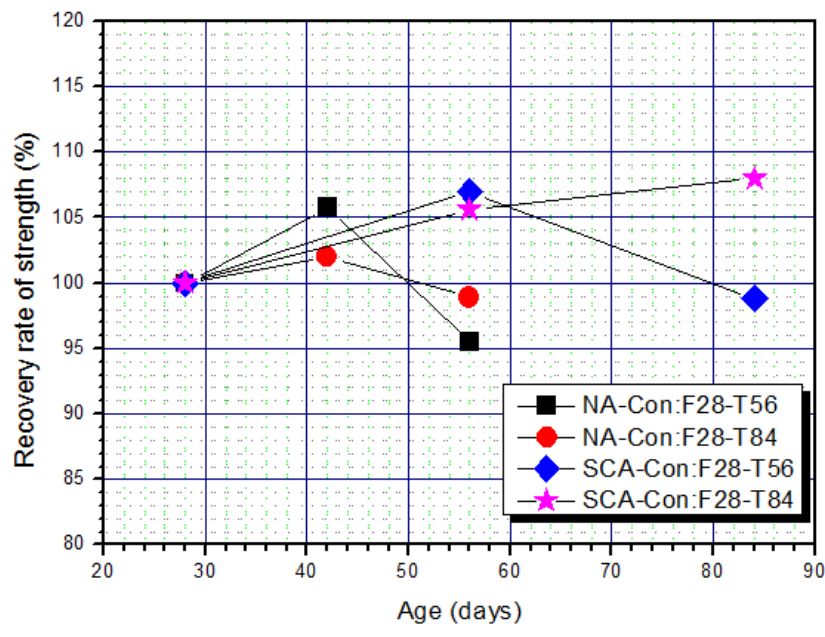

Figure 6. Recovery rate of strength at 28 days of initial age.

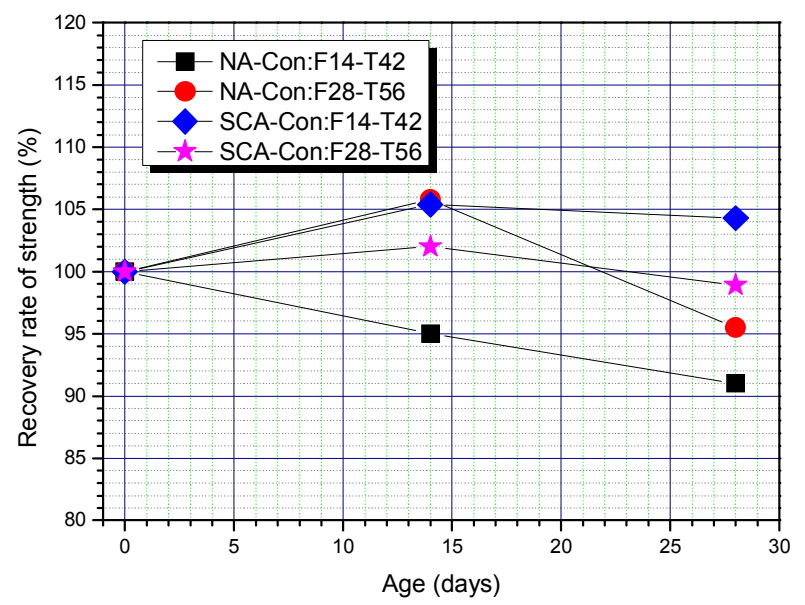

Figure 7. Changes of strength recovery rate according to the curing period (14 days).

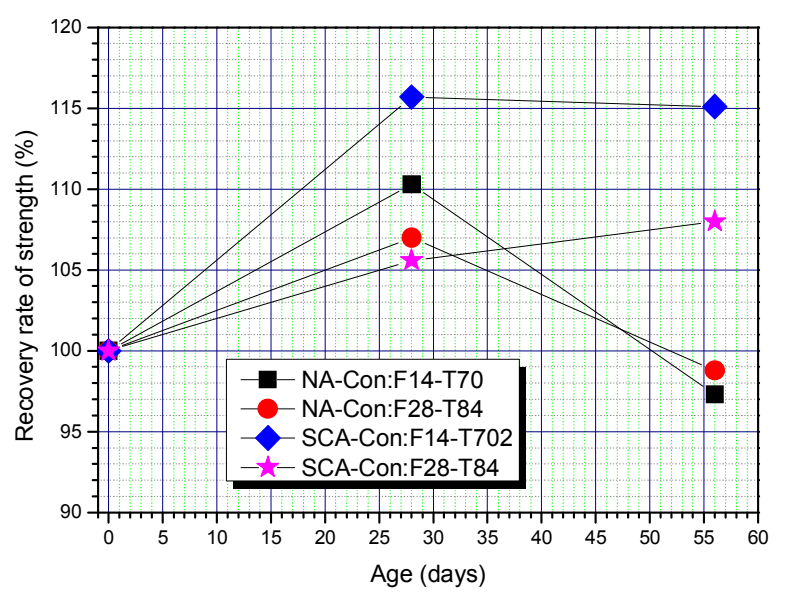

Figure 8. Changes of strength recovery rate according to the curing period (28 days).

Figure 7 and Figure 8 show the effects of the curing period after initial compression and after recompression on the strength recovery rate. According to these figures, the longer the curing period after initial compression and recompression, 
the higher the recovery rate for SAC-Con.

In the case of recompression $\left(3^{\text {rd }}\right.$-compression), the strength cannot be recovered after the 14th day of material age, while the 28th day of material age is much stronger than that of the recompression ( $2^{\text {nd }}$-compression).

On the other hand, in the case of NA-Con, the strength will not be restored even if the curing period is extended.

It was also found that the initial compression age affected the recovery of SAC-Con strength. Compared to the initial compression material age of 28 days, the strength recovery rate is higher at 14 days.

In other words, it is presumed that cracks caused by early age are more likely to be repaired. This trend was not clearly observed in ordinary concrete.

\subsection{Evaluation of Self-repair}

As mentioned above, it has been found that concrete mixed with special admixture will repair cracks caused by initial compression and restore strength. The strength recovery was usually observed in concrete, but the degree of recovery is greater with a special admixture. The hydration reaction of cement rapidly progresses to about 28 days of age and continues gradually.

Accordingly, cracks and other damages that occurred in the early years of material age are repaired to some extent by hydration of cement. This is shown in the results of this experiment. However, if further damage is done, it cannot be repaired only by hydration of cement, and the strength cannot be restored. On the other hand, if special admixture is used, the strength is restored by re-compression, indicating that the special admixture has contributed greatly to the recovery of the damage.

Within the age of the material examined in this experiment, it was found that even if a repair coating material was used as an admixture, the proper crystal growth promotion effect was maintained, and the concrete mixed with the admixture could be repaired. This effect is especially noticeable in young people, but it maintains its ability even at about three months old.

In this study, the curing conditions are water curing, and the results are best for the development of concrete strength and for the effect of promoting crystal growth of special admixture. Accordingly, further consideration is needed regarding self-repair performance under the curing conditions of actual construction.

Furthermore, it is necessary to consider the maintenance of self-repair capability for long-term materials older than one year.

\section{Conclusion}

In this study, the basic properties of concrete mixed with a repair coating material and the possibility of concrete having self-repair performance were examined. The results revealed the following.

1) The surface coating agent has a water-reducing effect and can improve the fluidity of fresh concrete by mixing.

2) The strength of concrete mixed with a surface coating agent has been improved by about $28 \%$ compared to NA-Con (without surface coating agent) mixed with the same material, and the watertightness has also been improved.

3) The above shows that using a repair coating material as an admixture is very effective in improving the performance of concrete. However, since the air volume of fresh concrete decreases due to the inclusion of a surface coating agent, further consideration should be given to the durability of concrete.

4) As a result of considering the recovery rate of the strength of damaged concrete, concrete mixed with a surface coating agent showed a greater recovery effect than concrete mixed with non-mixed concrete. This effect is greater with the age of the damaged material. This shows that even if the repair coating material is mixed as an admixture, the crystal proliferation effect is maintained, and it is confirmed that the concrete mixed with the admixture has self-repairing performance.

To produce more in-depth research results of this study, it is deemed necessary to conduct a long-term durability assessment study and to develop a chemical admixture.

\section{Acknowledgements}

This work is supported by the Korea Agency for Infrastructure Technology Advancement (KAIA) grant funded by the Ministry of Land, Infrastructure and Transport (Grant No.21POQW-B152343-03).

\section{References}

[1] Alrifile, M., et al, (2017), "Effect of Epoxy in Reducing Concrete Cracks" Journal of Environmental Science, 39 (2), 53-68.

[2] Lau, I., et al, (2018), "Critical Crack Depth in Corrosioninduced Concrete Cracking” ACI Structural Journal, 115 (4),

[3] Yu, C., et al, (2014), "The Effect of Concrete Cracks on Chloride Erosion" Applied Mechanics and Materials, 711 (1), 473-476.

[4] Beushausen, H., et al, (2019), "Performance-based approaches for Concrete Durability: State of the Art and Future Research Needs" Cement and Concrete Research, 119, 11-20.

[5] Moodi, F., et al, (2019), "Investigation on Mechanical and Durability Properties of Polymer and Latex-Modified Concretes" Construction and Building Materials, 191, 145-154.

[6] Onoue, K., et al, (2019), "Energy Consumption Characteristics of Concrete using Granulated Blast-Furnace Slag Sand related to Nucleation and Propagation of Microcracks" Construction and Building Materials, 218, 404-412.

[7] Abyaneh, S. D., et al, (2016), "Simulating the Effect of Microcracks on the Diffusivity and Permeability of Concrete using Three-Dimensional Model" Computational Material Science, 119, 130-143.

[8] Narayanan, A., et al, (2016), "Experimental Evaluation of Load induced Damage in Concrete from Distributed Microcracks to Localized Cracking on Electro-Mechanical Impedance Response of Bonded PZT" Construction and Building Materials, 105, 536-544. 
[9] Faber, M. H., et al, (2002), "Indicators of Inspection and Maintenance Planning of Concrete Structures" Structural Safety, 24 (2-4), 396.

[10] Lu, Y., et al, (2018), "Study on the Effect of Chloride Ion on the Early Age Hydration Process of Concrete by a NonContact Monitoring Method" Construction and Building Materials, 172, 499-508.

[11] Wang, X., et al, (2018), "Analysis of Hydration and Strength Optimization of Cement-Fly Ash-Limestone Ternary Blended Concrete" Construction and Building Materials, 166, 130-140.

[12] Dung, N. T., et al, (2018), "Development of MgO Concrete with Enhanced Hydration and Carbonation Mechanisms" Cement and Concrete Research, 103, 160-169.

[13] Ghoddousi, P., et al, (2017), "Study on Hydration Products by Electrical Resistivity for Self-Compacting Concrete with
Silica Fume and Metakaolin" Construction and Building Materials, 154, 219-228.

[14] Schepper, M. D., et al, (2014), "The Hydration of Cement Regenerated from Completely Recyclable Concrete" Construction and Building Materials, 60, 33-41.

[15] Geraldo, R. H., et al, "Study of Alkali-Activated Mortar used as Conventional Repair in Reinforced Concrete" Construction and Building Materials, 165, 914-919.

[16] Li, X., et al, (2019), "Modeling the Effects of Microcracks on Water Permeability of Concrete using 3D Discrete Crack Networks" Composites Structures, 210, 262-273.

[17] Han, B. Y., et al, (2005), “An Experimental Study on the Permeability of Reinforcement Concrete on Consideration of Pre-Loading" Journal of KSMI, 9 (3), 87-92. 